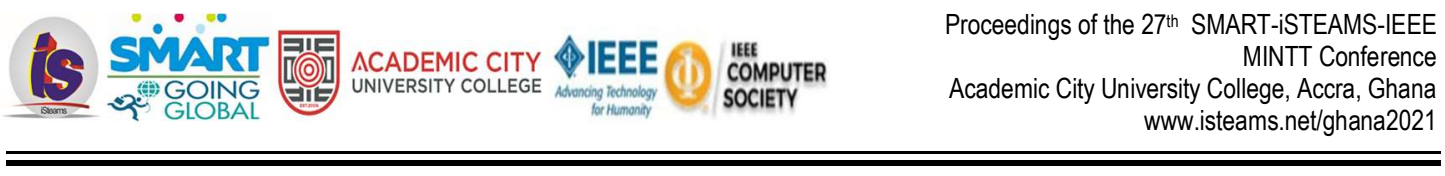

\title{
Describing Clothing by Semantic Attributes: A Heuristic Approach
}

\author{
1Opaleye, A.A. \& ${ }^{2}$ Kolawole, A. \\ 1,2Department of Industrial and Production Engineering \\ University of Ibadan, Nigeria \\ Emails: 1aa.opaleye@ui.edu.ng; 2k.kolawole@mail1.ui.edu.ng: \\ Phone: +2348030729147; +2348033773581
}

\begin{abstract}
Recognition of clothing categories is an appealing study to emerging applications such as computer aided fashion design for mass customization and e-commerce. In the study, the description and classification of clothing styles is established based on the preference index heuristic. Specifically, we take advantage of consumer's visual perception of clothing and their free choice description to; understand, characterise and, classify clothing styles. Evaluated on a dataset with 60 style samples of male clothing, the procedure demonstrates promising results in recognizing five clothing categories.
\end{abstract}

Keyword: Clothing, Semantic Attributes, Heuristics, Styles, Computer-Aided Fashion Design

Proceedings ReferenceFormat

Opaleye, A.A. \& Kolawole, A. (2021): Describing Clothing by Semantic Attributes: A Heuristic Approach. Proceedings of the 27th iSTEAMS

Multidisciplinary Innovations \& Technology Transfer (MINTT) Conference.Academic City University College, Accra, Ghana. June, 2021.

Pp 67-78 www.isteams.net/ghana2021. DOI - https://doi.org/ 10.22624/AIMS/iSTEAMS-2021/N27P8

\section{INTRODUCTION}

Analysis of clothing appearance has already attracted great interest in many research communities due to its wide application in computer aided fashion design, e-commerce and online advertising. Specifically, on online fashion marketplaces, displayed clothing designs has many attractive features which salesmen use alongside consumer's profile to recommend and arouse consumer's interest in purchasing. Unlike many online stores which offer a rich collection of categorized foreign clothing images with detailed attributes, the Nigerian clothing designs (NCD) remain limitedly displayed. For offline consumers, this may not be a challenge as cloth quality is evaluated primarily by the interaction of their visual and tactile perception.

However, consumers shopping online do not have the luxury of physical try-on. They rely on both product visual representation and the available information in search of a product with attributes which translate to their dimension of quality. This imposes an increasing challenge for consumers who have to choose from a large number of available clothing items to satisfy their specific need, and personal values. Consequently, there is an apparent disparity between imported and Nigerian clothing sold even on popular Nigeria's online fashion marketplace such as Jumia (McKinsey, 2013). For Nigeria to stem the growth of umemployment through the garment production enterprise, it must transit from the existing traditional bespoke clothing system to that which allows e-masscustomisation with its attendant advantages. It turns out that the only instrument for such transformation is an intelligent style and size selection system. 


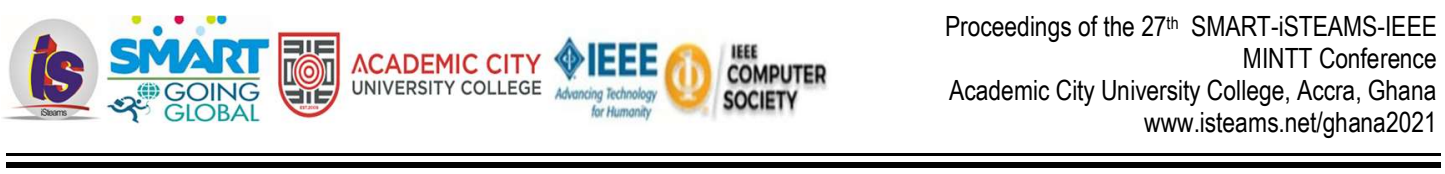

Analysis of foreign clothing styles has been employed as contexts in application such as smart recommendation, e-mass customisation and human identification problems (Anguelov et al., 2007; Chen et al., 2012; Yang, M., Yu, 2011). Borras et.al., (2003) provided a segmentation system which distinguish between five types of 2-piece clothing; Zhang et al.,(2008) developed a system to label clothing images with no collar, no/short sleeve, no button as T-shirts; images which has collar, short-sleeve, half-button as Polo-shirt; casual shirts has collar, short-sleeve, full-button while the business shirt has collar, long-sleeve, full-button. They used the computer vision and machine learning techniques to identify factors that human eyes perceive in term of clothing similarity from frontal-view outfit images.

Also, Yang and $\mathrm{Yu}$ (2011) propose a video content analysis system for tagging clothing class as suit, shirt, T-shirt, jeans, short pant, short skirt and long skirt in rea-time. Bossard et. al., (2012) use Random Forests, Support Vector Machine and Transfer Forests to recognise and classify the images into 15 clothing categories using various clothing feature and visual attributes. Similarly, Chen et al., (2012) learns a range of clothing categories with associated attributes details such collar presence, neckline shape etc. These classifications describe distinct clothing piece by body part segmentation. For example, Zhang et al., (2008) classification of men's shirts into; T-shirt, casual shirt and work shirt. This labelling system seems sufficient for foreign clothing items.

However, Nigerian clothing designs are usually a 2-piece or 3-piece item clothing collection of the same type of fabric. For instance, figure 1e represents a 3-piece design. Labelling each item of the design may be unrealistic for standardised ready to wear or e-mass customization of NCDs. In this study, we classify the Nigerian clothing styles and describe possible semantically meaningful attributes of each category. We propose to label categories of Nigerian clothing designs based on how consumers perceive and characterize the visual elements. That is, a set of clothing semantic attributes is generated to describe the visual appearance of Nigerian designs on human body. The classification model of the clothing styles is established using adapted preference index heuristic proposed by Charles-Owaba (1981). To our best knowledge, this is the first attempt to classify Nigerian clothing design with a description of associated attributes. This preliminary study has a great impact on many emerging applications for standardising Nigeria ready-to-wear, computer aided fashion design and improve online shopping recommendations.

\section{METHOD APPLIED IN THIS STUDY}

One of the major challenges of this study is that there is no database to use as a standard set, so the methodology is in two stages; data generation and preparation and, data classification.

\subsection{Data Generation and Preparation}

In consideration that there is no database on Nigeria clothing designs, we used sixty (60) male clothing images of styles from famous domestic shopping website as our sample set. The set consist of clothing with significant variation in types, styles, colours and patterns. Twenty-three participants were invited for a free choice description of the sample set. Each participant was adequately informed of the study aim and was asked to independently write a description for ten randomly selected style samples. They were told to write the style description for a hypothetical bespoke tailor as comprehensively as possible. Such generation is essential because it enables us to understand how consumers perceive and describe what they see in styles. Figure 1.0 shows the frontal view of some of the NCDs included in the study. 
Picture resolution and pose of persons captured in the images may likely influence participants classification at this stage. However, we leave this for future research. The free choice description of clothing features were marked and reorganised with the help of some fashion experts. The experts developed a list of attributes describing different key elements of designing clothing. Finally, all the style samples were defined based on the attribute descriptors.

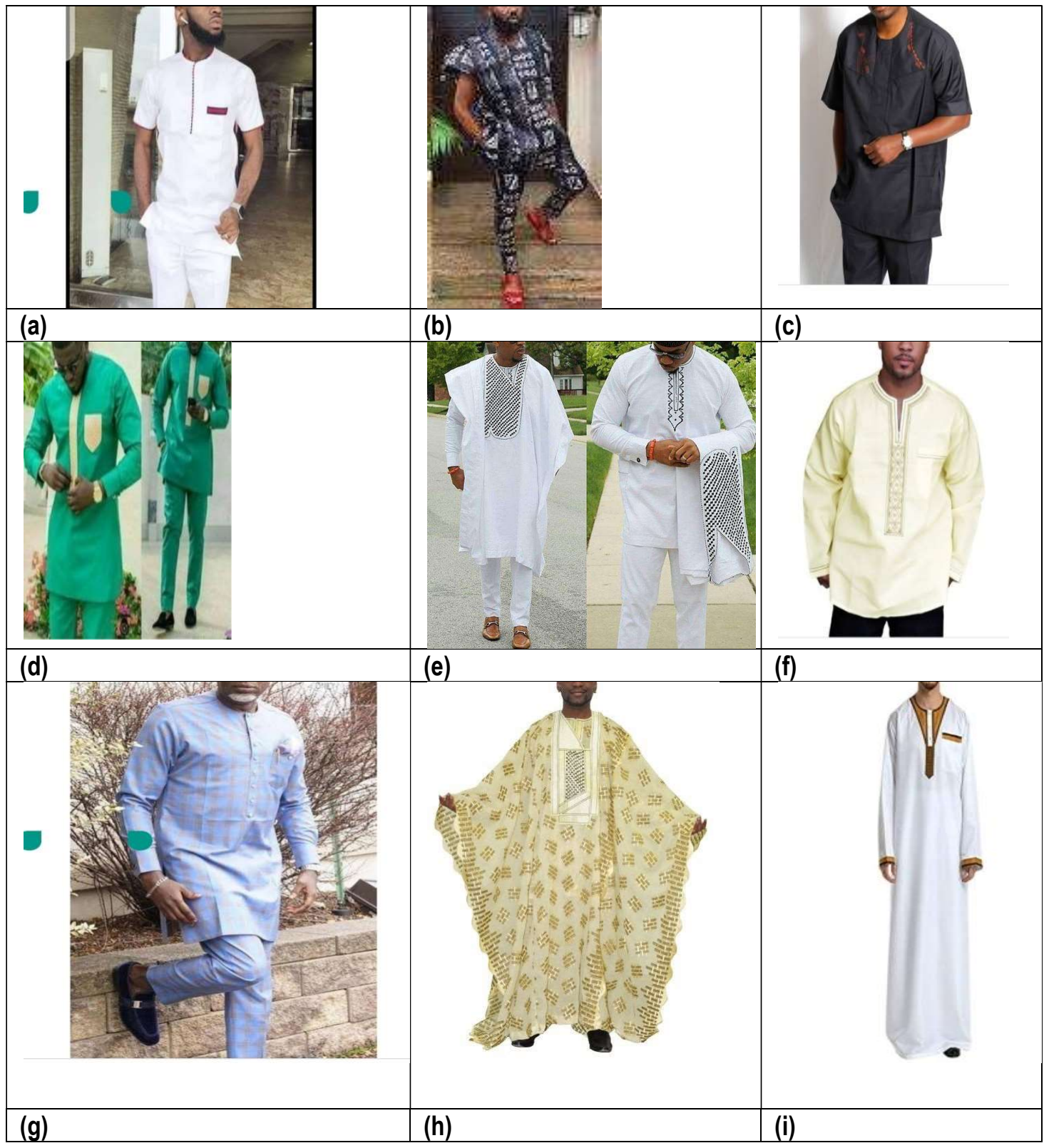

Figure 1 : Example of Images Used as Sample Set 


\subsection{Data Classification}

The classification process is based on the preference index heuristic which works in two stages. This includes the creation of "N" style class and assignment of styles into class. The two stages are based on improving overall preference index function $\mathrm{H}$. The step by step procedure for preference index heuristic is as follows;

Step 1: Identify styles and associated semantic attributes or design characteristics

Step 2: Compute similarity coefficient $\left(R_{i j}\right)$ between styles

$$
R_{i j}=\frac{\kappa\left(r_{i} \cap r_{j}\right)}{\kappa\left(r_{i} \cup r_{j}\right)} ; \quad \mathbf{0} \leq R_{i j} \leq 1
$$

Where $\kappa\left(r_{i} \cap r_{j}\right)$; denotes number of attributes common to styles $\mathrm{i}$ and $\mathrm{j}$ or intersecting styles $i$ and $i$ while $\kappa\left(r_{i} \cup r_{j}\right)$; denotes union of attributes of style $\mathrm{i}$ and $\mathrm{j}$

If

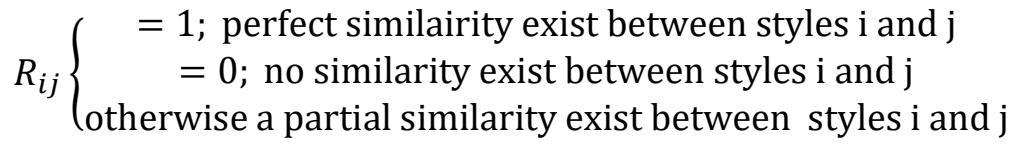

while $R_{i j}=R_{j i}=$ synmetric property of styles

Step 3: Initiate classification parameters as follows; n: number of styles;

$\mathrm{N}$ : Number of classes of styles; $\quad$ F: current set of candidate styles ;

$\overline{\mathrm{N}}$ : current number of classes of styles; Q: current number of styles assigned into class

Step 4: Create the first two base style classes $\left(\pi_{k}\right)$ : Select minimum $R_{i j}$ and assign style $i$ into $\pi_{1}$ and $\pi_{2} ;$ where $k=1,2, \ldots N$. (Ties may be broken arbitrarily)

Step 5: Update $F, N$, and $Q$

Step 6: If $N=\bar{N}$, go to step 8 else go to step 5 .

Step 7: Compute preference index $\left(\emptyset_{i}\right)$ for all possible candidates' styles and assign style $i$ with minimum $\emptyset_{i \alpha}$ to the next class group. Go to step 5. Preference index between styles $\left(\emptyset_{i \alpha}\right)$ represent the net accuracy style $i$ and $\alpha$ will contribute to the overall classification if assigned to the same group.

$$
\emptyset_{i \alpha_{k}}=R_{i \alpha^{-}}-\frac{\sum_{j=1}^{n-2} R_{i j}+\sum_{j=1}^{n-2} R_{\alpha j}}{2(n-2)} ; i \neq \alpha \neq j
$$

Preference index $i, \emptyset_{i}=\sum_{k=1}^{\bar{N}} \emptyset_{i \alpha_{k}} ; \quad \sum_{j=1}^{n_{-2}} R_{i j}$; sum of the similarity coefficient of $i$ to all other styles $j$ excluding $\alpha ; \quad \sum_{j=1}^{n_{-2}} R_{\alpha j}$; sum of the similarity coefficient of $\alpha$ to all other styles $j$ excluding $i$ Note that $\alpha$ is a style in an existing class. 
Step 8: Compute preference index between candidate styles and class groups $\left(\dot{Y}_{i k}\right)$. Select maximum $\dot{Y}_{i k}$ and assign $i$ to class $k$. assign remaining styles into class.

- Preference index of style $i$ to class $k\left(\dot{Y}_{i j}\right)$ represent the net accuracy that will result if style $i$ is assigned to class $k$.

$$
; \quad \dot{Y}_{i k}=\frac{\sum_{j=1}^{n_{k}} R_{i j}}{n_{k}}-\frac{\sum_{\tau=1}^{n-n_{k-1} R_{i \tau}}}{n-n_{k-1}} \quad j \in g_{k} ;
$$

$n_{k}$ represent the number of styles in class $k$ excluding $i$

$n-n_{k-1}$, : number of styles in other class not $k$

$\sum_{\tau=1}^{n-n_{k-1}} R_{i \tau}$ : represent the sum of the similarity coefficient of $i$ to all other styles not in class $k$

Step 9: Update $F$ and $Q$

Step 10: If $Q=n$, stop else go to step 8 .

\section{PRESENTATION AND DISCUSSION OF RESULTS}

The research sample included 23 male participants whose demographic characteristics are presented in Table 1.0. Students made up $60.9 \%$ of the sample, the others being academia $(21.7 \%)$, health professional $(4.3 \%)$ and business owner (13\%). There were no participants below 20years of age, those between 20 and 30 years $(52.2 \%)$ comprised the largest age group in the sample, followed by those between 30-40years $(34.8 \%)$, between 40 and 50 years $(8.7 \%)$ and above $50 y$ ears is only $4.3 \%$ of the participants.

Table 1.0 Demographic Characteristic of Research Participants

\begin{tabular}{lll}
\hline Demographic Characteristic & & Participants \\
\hline Age & Below 20 & $0 \%$ \\
& $20-30$ & $52.2 \%$ \\
& $30-40$ & $34.8 \%$ \\
Highest academic qualification & $40-50$ & $8.7 \%$ \\
& Above 50 & $4.3 \%$ \\
Professional status & High School & $17.4 \%$ \\
& First Degree & $47.8 \%$ \\
& Postgraduate & $34.8 \%$ \\
& Others & $0 \%$ \\
& Student & $60.9 \%$ \\
& Academia & $21.7 \%$ \\
& Health Professional & $4.3 \%$ \\
\hline
\end{tabular}


3.1 Free Choice Description of Style attributes

Each participant describes ten (10) randomly chosen style samples out of 60 . Criteria used were not predefined; as a result, some participants gave insufficient description of the clothing features while most of the participants provide detailed explanation on the attributes they considered important. Table 2.0 shows the summary of some of the descriptions. Descriptors representing fabric was excluded as we do not consider the fabric in this study (we leave that for future study). Those representing similar attributes were grouped into a subclass. For example, O-Neck, Circular and round neck are descriptors of same neckline. The most occurring word in that class was used as the representative word. Other neckline such as V-neck, U-neck, High-neck (stand collar) and Business/shirt collar were considered in different subclasses. As a result, the neckline has five different types of attributes representing the sample set. Some of the words and associated descriptions representing the neckline and upper clothing is as shown in Figure 2.0 and Figure 3.0.

Table 2.0: Descriptors of Semantic Attributes

\begin{tabular}{|c|c|c|c|c|c|c|}
\hline Neckline & Decorative & Sleeve & Upper Clo & hing & Trousers & \\
\hline V-neck & $\begin{array}{l}\text { Embroidery } \\
\text { design }\end{array}$ & Short & $\begin{array}{l}\text { Smart } \\
\text { upper } \\
\text { wear }\end{array}$ & Short length & $\begin{array}{l}\text { Normal } \\
\text { trouser length }\end{array}$ & $\begin{array}{l}\text { Round- } \\
\text { neck }\end{array}$ \\
\hline Oval & $\begin{array}{l}\text { Simple } \\
\text { Embroidery }\end{array}$ & $3 / 4$ sleeve & $\begin{array}{l}\text { Fitted } \\
\text { wear }\end{array}$ & $\begin{array}{l}\text { Normal } \\
\text { length }\end{array}$ & Pencil trouser & $\begin{array}{l}\text { Neck which } \\
\text { has a } \\
\text { triangle } \\
\text { shape }\end{array}$ \\
\hline Round & $\begin{array}{l}\text { Embroidery } \\
\text { with same } \\
\text { colour as fabric }\end{array}$ & Long sleeve & $\begin{array}{l}\text { Not very } \\
\text { smart } \\
\text { wear }\end{array}$ & Hip length & $\begin{array}{l}\text { Trouser with } \\
\text { free mouth }\end{array}$ & Knee length \\
\hline O-Neck & $\begin{array}{l}\text { Multicolour } \\
\text { embroidery }\end{array}$ & Shirt Sleeve & $\begin{array}{l}\text { Semi fit } \\
\text { wear }\end{array}$ & $\begin{array}{l}\text { Between } \\
\text { hip and } \\
\text { knee }\end{array}$ & Baggy & $\begin{array}{l}\text { Width } \\
\text { between } \\
\text { elbow and } \\
\text { wrist }\end{array}$ \\
\hline Circular & Simple design & Free sleeve & $\begin{array}{l}\text { Loose } \\
\text { wear }\end{array}$ & Not too long & $\begin{array}{l}\text { Straight } \\
\text { trouser }\end{array}$ & $\begin{array}{l}\text { Ankle } \\
\text { length }\end{array}$ \\
\hline High neck & $\begin{array}{l}\text { Flashy coloured } \\
\text { design }\end{array}$ & Buba sleeve & $\begin{array}{l}\text { Free } \\
\text { wear }\end{array}$ & Knee length & & \\
\hline $\begin{array}{l}\text { Bishop } \\
\text { Neck }\end{array}$ & $\begin{array}{l}\text { Simple } \\
\text { decorative } \\
\text { design }\end{array}$ & $\begin{array}{l}\text { Native } \\
\text { sleeve }\end{array}$ & & $\begin{array}{l}\text { Ankle } \\
\text { length }\end{array}$ & & \\
\hline Shirt Collar & $\begin{array}{l}\text { Hausa } \\
\text { Embroidery }\end{array}$ & $\begin{array}{l}\text { Extended } \\
\text { sleeve }\end{array}$ & & Full length & & \\
\hline Not sure & $\begin{array}{l}\text { Machine } \\
\text { Embroidery }\end{array}$ & & & 3/4 length & & \\
\hline & $\begin{array}{l}\text { Attached } \\
\text { clothing of } \\
\text { different colour }\end{array}$ & & & & & \\
\hline
\end{tabular}




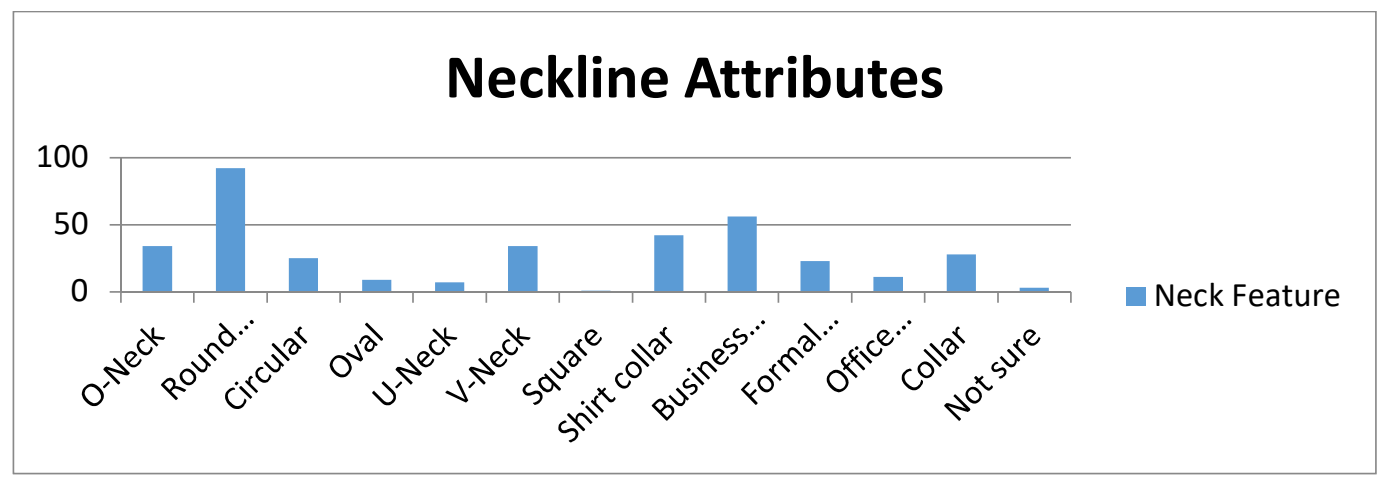

Figure 2: Descriptors for Neckline

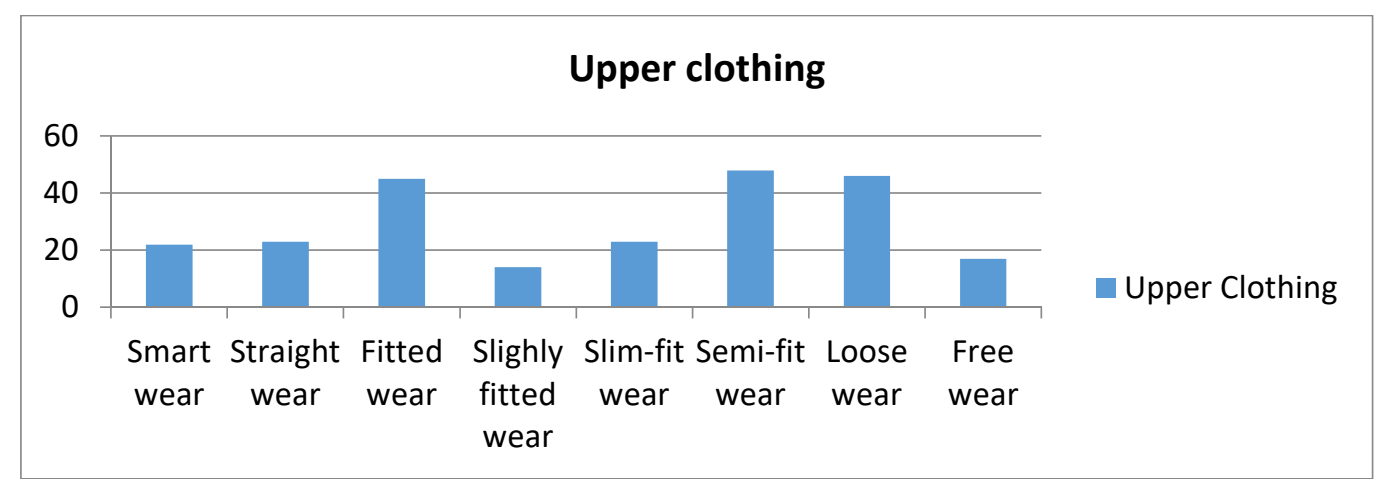

Figure 3: Descriptors of fit for the Upper clothing

The words (or group of words) were rearranged into attribute categories relating to the key elements of designing a collection. Identified elements of design include; number of pieces in the style set, upper body clothing, lower body clothing and the full body clothing. Some styles consist of 2-pieces (upper and lower body clothing) while others have the 3-pieces (upper, lower and the full body clothing). Attributes relating to the upper body clothing includes; the neckline, decorative design, cloth fit etc. Table 3.0 shows the breakdown of the identified design elements and attributes. 
Table 3.0: Description of Attributes

\begin{tabular}{|c|c|c|c|c|c|c|c|c|c|}
\hline Attributes & Elem & Co & \multicolumn{7}{|c|}{ Sub-categories of Attributes } \\
\hline $\begin{array}{l}\text { Number of pieces in the style } \\
\text { set }\end{array}$ & & A1 & \multicolumn{2}{|c|}{ 2-Piece set (1) } & \multicolumn{4}{|c|}{ 3-Piece set (2) } & \\
\hline Neckline 1 (Upper clothing) & & $\mathrm{A} 2$ & $\begin{array}{l}\text { V-neck } \\
\text { shape (1) }\end{array}$ & $\begin{array}{l}\text { O-neck } \\
\text { shape (2) }\end{array}$ & \multicolumn{3}{|c|}{ U-neck shape (3) } & $\begin{array}{l}\text { Business } \\
\text { collar(4) }\end{array}$ & $\begin{array}{l}\text { Bish } \\
\text { op/ } \\
\text { stand } \\
\text { collar } \\
\text { (5) }\end{array}$ \\
\hline Type of decorative design & & A3 & None (1) & $\begin{array}{l}\text { Hand-made } \\
\text { (2) }\end{array}$ & \multicolumn{3}{|c|}{ Machine-made(3) } & \multicolumn{2}{|c|}{ Other Attachments (4) } \\
\hline Volume of decorative design & & A4 & None (1) & Simple (2) & \multicolumn{3}{|c|}{ Medium (3) } & $\begin{array}{l}\text { Full/Complex } \\
\text { (4) }\end{array}$ & \\
\hline Design colour & & A5 & None (1) & \multicolumn{4}{|c|}{ Same as fabric colour (2) } & Contrast (3) & \\
\hline Sleeve Type & & A6 & $\begin{array}{l}\text { Sleeveles } \\
\mathrm{s}(1)\end{array}$ & \multicolumn{2}{|c|}{ Sleeve with cuff(2) } & $\begin{array}{l}\text { Relaxed } \\
\text { Sleeve(3 }\end{array}$ & & \multicolumn{2}{|c|}{ Extended sleeve (4) } \\
\hline Sleeve Length & & A7 & $\begin{array}{l}\text { Sleeveles } \\
\mathrm{s}(1)\end{array}$ & $\begin{array}{l}\text { Between } \\
\text { shoulder } \\
\text { \& the Elbow }\end{array}$ & $\begin{array}{l}\text { the } \\
\text { 2) }\end{array}$ & $\begin{array}{l}\text { Elbow } \\
\text { length }\end{array}$ & & $\begin{array}{l}\text { Between the } \\
\text { Elbow \& } \\
\text { the wrist (4) }\end{array}$ & $\begin{array}{l}\text { Wrist } \\
\text { Leng } \\
\text { th } \\
\text { (5) }\end{array}$ \\
\hline Cloth Fit & \multirow[b]{2}{*}{ 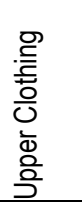 } & A8 & Fitted (1) & \multicolumn{2}{|l|}{ Semi-fit (2) } & \multicolumn{2}{|c|}{ Loose (3) } & & \\
\hline Cloth Length & & A9 & Hipline (1) & \multicolumn{2}{|c|}{$\begin{array}{l}\text { Between the hip } \\
\text { and knee(2) }\end{array}$} & \multicolumn{2}{|c|}{$\begin{array}{l}\text { Knee length } \\
(3)\end{array}$} & $\begin{array}{l}\text { Between the } \\
\text { knee \& } \\
\text { ankle (4) }\end{array}$ & $\begin{array}{l}\text { Ankl } \\
\mathrm{e} \\
\text { lengt } \\
\mathrm{h}(5)\end{array}$ \\
\hline Trouser Type & $\begin{array}{l}\text { Lower } \\
\text { Body } \\
\text { Clothi } \\
\text { ng }\end{array}$ & $\begin{array}{l}\text { A1 } \\
0\end{array}$ & \multicolumn{3}{|c|}{$\begin{array}{lll}\text { Smart } & \text { with } & \text { pencil } \\
\text { girth (1) } & & \end{array}$} & $\begin{array}{l}\text { Smart } \\
\text { girth (2) }\end{array}$ & \multicolumn{2}{|c|}{ with straight } & Free \\
\hline $\begin{array}{l}\text { Neckline 2(Free flowing } \\
\text { gown) }\end{array}$ & \multirow{6}{*}{ 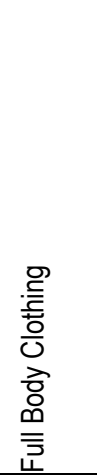 } & $\begin{array}{l}\mathrm{A} 1 \\
1\end{array}$ & None (1) & \multicolumn{3}{|c|}{ Round-neck type } & \multicolumn{3}{|c|}{ Triangle-neck type } \\
\hline Type of decorative design2 & & $\begin{array}{l}\text { A1 } \\
2\end{array}$ & None (1) & \multicolumn{3}{|c|}{ Hand-made (2) } & \multicolumn{3}{|c|}{ Machine-made (3) } \\
\hline Volume of decorative design2 & & $\begin{array}{l}\mathrm{A} 1 \\
3\end{array}$ & None (1) & \multicolumn{2}{|l|}{ Simple (2) } & $\begin{array}{l}\text { Medium } \\
\text { (3) }\end{array}$ & \multicolumn{2}{|c|}{ Full/Complex(4) } & \\
\hline $\begin{array}{l}\text { Design colour with respect to } \\
\text { the fabric colour2 }\end{array}$ & & $\begin{array}{l}\text { A1 } \\
4\end{array}$ & None (1) & $\begin{array}{l}\text { Same as } \\
\text { colour (2) }\end{array}$ & fabric & $\begin{array}{l}\text { Contras } \\
\mathrm{t}(3)\end{array}$ & & & \\
\hline Cloth Width & & $\begin{array}{l}\text { A1 } \\
5\end{array}$ & None (1) & \multicolumn{3}{|c|}{ Mid way forearm (2) } & \multicolumn{3}{|c|}{ Armspan (3) } \\
\hline Cloth Length & & $\begin{array}{l}\text { A1 } \\
6\end{array}$ & None (1) & \multicolumn{2}{|c|}{ Knee length (2) } & $\begin{array}{l}\text { Between } \\
\text { knee } \\
\text { ankle (3) }\end{array}$ & & \multicolumn{2}{|l|}{ Ankle length(4) } \\
\hline
\end{tabular}

Some of these attributes were sub-grouped and named according to the most frequently used word. We also accounted for all respondents' implicit descriptions by creating representative subgroups. For instance, sentences like 'simple machine embroidery decoration' and 'light blue embroidery on deep blue fabric' described the decorative feature in terms of the; type of decorative design, colour of the design with respect to the fabric colour and the fullness or complexity of the design. As a result, sixteen types of attributes with a total of 50 subclass were extracted. Figure 4.0 shows a segment of the attribute distribution in the dataset. 


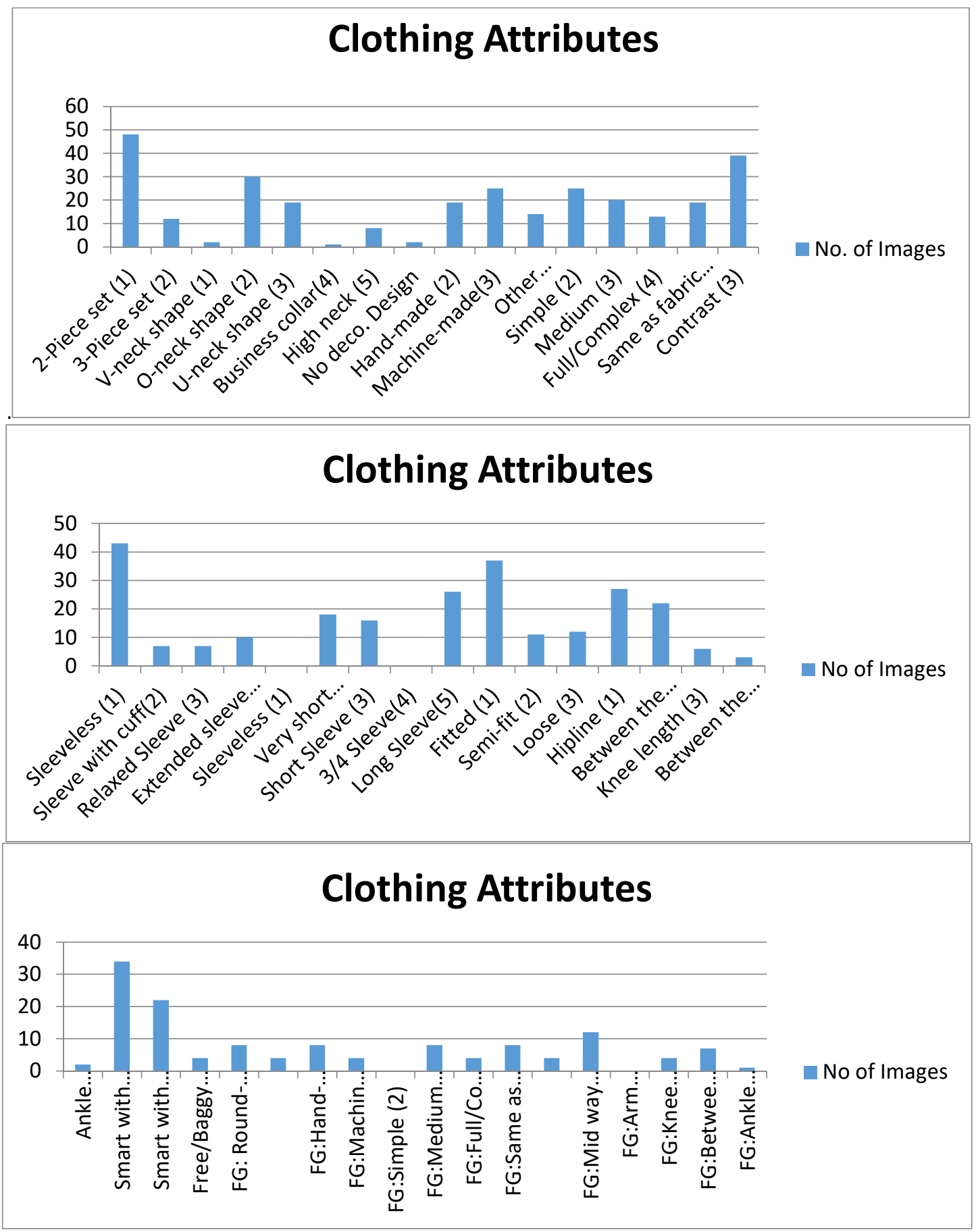

Figure 4.0. Attribute distribution with respect to the upper clothing, lower clothing and the full body clothing 
After the free choice description and processing of word groups, twelve fashion experts were invited to manually reannotate the attributes of styles in order to describe the clothing as compactly as possible. The categorical attribute labels were used as a guide to generate data for the classification process.

3.2 Heuristic Classification

According to the heuristic procedure, the style samples and associated attributes were defined ( in subsection 3.1) and similarity coefficient determined. The similarity coefficient for eight (8) different styles in the data set is presented in Table 4.0. We arbitrarily chose the number of classes of style and set the initiating parameters as $(F=60, \bar{N}=0,0)$.

Table 4.0: Similarity Coefficient

\begin{tabular}{lllllllll}
\hline Style Samples & 1 & 2 & 3 & 4 & 5 & 6 & 7 & 8 \\
\hline 1 & - & 0.818182 & 0.818182 & 0.272727 & 0.636364 & 0.272727 & 0.545455 & 0.181818 \\
2 & 0.818182 & - & 1 & 0.363636 & 0.727273 & 0.363636 & 0.545455 & 0.181818 \\
3 & 0.818182 & 1 & - & 0.363636 & 0.727273 & 0.363636 & 0.545455 & 0.181818 \\
4 & 0.272727 & 0.363636 & 0.363636 & - & 0.272727 & 1 & 0.454545 & 0.727273 \\
5 & 0.636364 & 0.727273 & 0.727273 & 0.272727 & - & 0.272727 & 0.272727 & 0.090909 \\
6 & 0.272727 & 0.363636 & 0.363636 & 1 & 0.272727 & - & 0.454545 & 0.727273 \\
7 & 0.545455 & 0.545455 & 0.545455 & 0.454545 & 0.272727 & 0.454545 & - & 0.363636 \\
8 & 0.181818 & 0.181818 & 0.181818 & 0.727273 & 0.090909 & 0.727273 & 0.363636 & - \\
\hline
\end{tabular}

Table 5.0 shows that a total of 27 symmetric relations with a $\min \left(R_{i j}\right)=0.09$ exist in the set. Thus the tie was arbitrarily broken and style 5 and 8 are assigned to class $1\left(\pi_{1}=[5]\right.$ ) and $2 \pi_{2}=[8]$ respectively.

Table 5.0: Minimum Similarity Values

\begin{tabular}{|c|c|c|c|c|c|c|c|c|c|c|c|c|}
\hline $\mathrm{i} / \mathrm{j}$ & 5 & 8 & 17 & 18 & 23 & 26 & 29 & 36 & 39 & 45 & 46 & 55 \\
\hline 5 & - & 0.09 & 0.09 & 0.09 & 0.09 & 0.09 & 0.09 & 0.09 & 0.09 & 0.09 & 0.09 & 0.09 \\
\hline 8 & & - & & & & & & & & & 0.09 & 0.09 \\
\hline 17 & & & - & & & & & & & & 0.09 & 0.09 \\
\hline 18 & & & & - & & & & & & & 0.09 & 0.09 \\
\hline 23 & & & & & - & & & & & & 0.09 & 0.09 \\
\hline 26 & & & & & & - & & & & & 0.09 & 0.09 \\
\hline 29 & & & & & & & - & & & & 0.09 & 0.09 \\
\hline 36 & & & & & & & & - & & & 0.09 & 0.09 \\
\hline 39 & & & & & & & & & - & & 0.09 & 0.09 \\
\hline
\end{tabular}

The new parameters are $(F=58, \bar{N}=2,2)$, since $N \neq N$, a new class is formed using the minimum preference index as shown in equation (2). Table 6.0 shows the preference index for all candidate style with the minimum $\left(\emptyset_{i}\right)=-0.319$ for styles 31 and 32 . Style 31 is arbitrarily chosen as the base style for group 3. 
Table 6.0: Preference Index

\begin{tabular}{llllllllll}
\hline$i$ & $\emptyset_{i}$ & $i$ & $\emptyset_{i}$ & $i$ & $\emptyset_{i}$ & $i$ & $\emptyset_{i}$ & $i$ & $\emptyset_{i}$ \\
\hline 1 & 0.041 & 15 & 0 & 27 & 0.041 & 39 & -0.061 & 51 & 0.014 \\
2 & 0.077 & 16 & 0 & 28 & -0.113 & 40 & -0.067 & 52 & 0.052 \\
3 & 0.077 & 17 & 0.114 & 29 & -0.061 & 41 & -0.047 & 53 & 0.052 \\
4 & -0.047 & 18 & 0.114 & 30 & -0.047 & 42 & -0.067 & 54 & 0.077 \\
6 & -0.047 & 19 & -0.047 & 31 & -0.319 & 43 & -0.113 & 55 & 0.331 \\
7 & -0.229 & 20 & -0.067 & 32 & -0.319 & 44 & -0.285 & 56 & -0.047 \\
9 & 0.014 & 21 & 0.077 & 33 & -0.229 & 45 & -0.061 & 57 & -0.230 \\
10 & -0.113 & 22 & -0.113 & 34 & -0.285 & 46 & 0.332 & 58 & -0.113 \\
11 & 0.077 & 23 & 0.114 & 35 & -0.230 & 47 & -0.227 & 59 & -0.067 \\
12 & 0.041 & 24 & 0 & 36 & 0.114 & 48 & -0.047 & 60 & -0.047 \\
13 & -0.047 & 25 & 0 & 37 & -0.067 & 49 & -0.133 & & \\
14 & -0.113 & 26 & -0.061 & 38 & 0 & 50 & 0 & & \\
\hline
\end{tabular}

Repeating steps 5-7, the new parameters are $(F=57, \bar{N}=3,3)$, since $N \neq N$, a new class is formed using the minimum preference index as shown in equation (2). The new minimum preference index $\left(\emptyset_{i}\right)=$ -0.240 for styles 47 and the updated parameters are $(F=56, \bar{N}=4,4)$. Since $N \neq N$, the next repetition resulted in a minimum preference index as $\left(\emptyset_{i}\right)=-0.292$ according to equation (2). Style 40 was arbitrarily chosen as the base style for class 5 out of candidate styles 26, 29, 40 and 46 with $=-0.292$ .All other styles were assigned to classes using step 8-10 as shown in Table 7.0.

Table 7.0: Styles Classification

\begin{tabular}{lllll}
\hline Class 1 & Class 2 & Class 3 & Class 4 & Class 5 \\
\hline $46,55,2,3,11$ & $8,17,18,23,36$, & $31,32,7,33$ & $26,29,39,45$ & $47,16,52,53$ \\
$21,1,12,27$, & $9,51,58,10,14$, & & $15,24,25,38$ & $49,20,37,40$, \\
54 & & & & \\
& $22,28,43,4,6$ & & $50,35,57$ & $42,59,13,30$ \\
& 19,60 & 34 & $48,56,5,41,44$ \\
\hline
\end{tabular}

All the ten styles in class one are three-piece designs. Class two consists of a total of seventeen short sleeved styles. Fifteen of the stylesare two -piece fitted styles with short relaxed sleeve while the othertwo are two -piece fitted styles with short extended sleeve. Class three consists only four styles which are twopiece design with extended sleeve of varying length.Class four consists of twelve styles which are long sleeved design with cuff while class five is not distinctly defined in attributes. The number of pieces in style set and the sleeve type seems to be a unique distinguishing attribute among classes 1,2, 3 and 4 while class 5 is a mix of styles. 


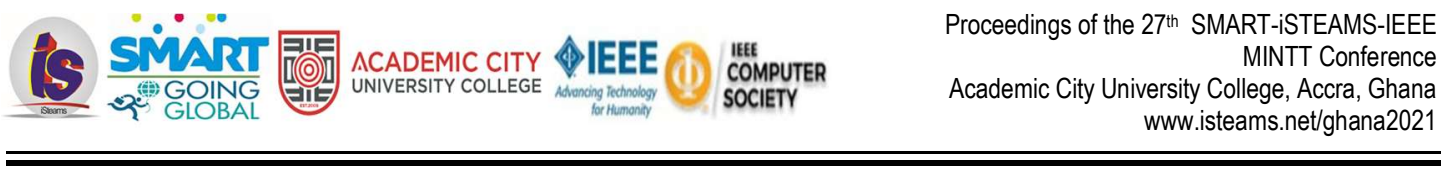

\section{CONCLUSION}

The aim of the study is to describe the semantic attributes of Nigeria clothing design using a free choice description. Combined with the advantages of the preference index heuristic, we learned the item representation in semantic attribute space under a similarity learning framework. The experimental study on the real images of clothing dataset clearly demonstrates promising results. The study indicates that the 60 sample styles can be grouped into five (5) categories. All classes except class 5 have distinct attributes for easy consumer selection.

This is a preliminary study and it is expected that an automatic high level extraction of semantic attributes may provide more accurate style categories.We aim to lay the groundwork to facilitate a system for online retailing of ready to wear and e-mass customization of Nigerian clothing designs.

\section{Acknowledgement}

The authors would like to acknowledge the funding received from Nigerian TETFund National Research Grant 2019 in carrying out this study

\section{REFERENCES}

1. Anguelov, D., Lee, K. C., Gökturk, S. B., \& Sumengen, B. (2007). Contextual identity recognition in personal photo albums. 2007 IEEE Conference on Computer Vision and Pattern Recognition, 1-7,. https://doi.org/10.1109/CVPR.2007.383057

2. Borras, A., Tous, F., Llados, J., and Vanrell, M., Borras, A., Tous, F., Llados, J., and Vanrell, M. (2003). High-Level Clothes Description Based on Colour-Texture and Structural Features. In Perales F.J., Campilho A.J.C., de La Blanca N.P., Sanfeliu A. (Eds) Pattern Recognition and Image Analysis. IbPRIA 2003. Lecture Notes in Computer Science, Vol 2652. Springer, 108-116.

3. Bossard, L., Dantone, M., Leistner, C., Wengert, C., Quack.T., and L. V. G. (2012). Apparel classification with style. Asian Conference on Computer Vision, 321-335.

4. Charles-Owaba, O. E. (1981). Analysis of the parts/machines grouping problem in group technology manufacturing systems. Texas Tech University, USA.

5. Chen, H., Gallagher, A., \& Girod, B. (2012). Describing Clothing by Semantic Attributes. European Conference on Computer Vision, 609-623.

6. McKinsey. (2013). Lions go digital: The Internet's transformative potential in Africa. McKinsey Global Institute.

http://www.mckinsey.com/insights/high_tech_telecoms_internet/lions_go_digital_the_internets_tr ansformative_potential_in_africa.

7. Yang, M., Yu, K. (2011). Real-time clothing recognition in surveillance videos. 2011 18th IEEE International Conference on Image Processing, 2937-2940. https://doi.org/doi: 10.1109/ICIP.2011.6116276.

8. Zhang, W., Begole, B., Chu, M., Liu, J., \& Yee, N. (2008). Real-time clothes comparison based on multi-view vision. 2008 2nd ACM/IEEE International Conference on Distributed Smart Cameras, ICDSC 2008, 1-10. https://doi.org/10.1109/ICDSC.2008.4635727. 